\title{
Association of markers of endothelial dysregulation Ang1 and Ang2 with acute kidney injury in critically ill patients
}

\author{
Cassianne Robinson-Cohen ${ }^{1 *}$, Ronit Katz ${ }^{1}$, Brenda L. Price ${ }^{1,2}$, Susanna Harju-Baker ${ }^{3}$, Carmen Mikacenic ${ }^{3}$, \\ Jonathan Himmelfarb ${ }^{1}$, W. Conrad Liles ${ }^{4}$ and Mark M. Wurfel ${ }^{3}$
}

\begin{abstract}
Background: The role of endothelial dysregulation with acute kidney injury (AKI) in critically ill patients is unclear. Methods: We retrospectively assessed the associations of AKI with biomarkers of endothelial function and inflammation among 948 subjects admitted to the intensive care unit (ICU) at Harborview Medical Center (Seattle, WA, USA). From plasma obtained within $24 \mathrm{~h}$ of enrollment, we measured angiopoietin (Ang)-1 and Ang-2 alongside biomarkers of inflammation, including interleukin (IL)-6, IL-17 and granulocyte colony-stimulating factor. We tested for associations between standardized concentrations of biomarkers and AKI, defined by serum creatinine, from ICU admission to up to 7 days later.

Results: All biomarkers of inflammation and endothelial dysfunction were associated with AKI. After adjustment for demographics, comorbidities, and IL-6 concentration, every standard deviation of Ang-1 concentration was associated with a $19 \%$ lower risk of AKI (relative risk $(\mathrm{RR})=0.85,95 \%$ confidence interval $(\mathrm{Cl}) 0.77-0.93, p<0.001$ ). Conversely, higher Ang-2 concentration was associated with higher risk of AKI (RR per standard deviation $=1.17$, $95 \% \mathrm{Cl} 1.13-1.22, p<0.001)$.

Conclusions: In critically ill patients, plasma concentration of the endothelial growth factors Ang-1 and Ang-2 are associated with AKI, independently of inflammation.
\end{abstract}

Keywords: Acute kidney injury, Endothelial dysfunction, Endothelial dysregulation, Sepsis

\section{Background}

Acute kidney injury (AKI) is a common complication of sepsis and the systemic inflammatory response syndrome (SIRS), and is highly associated with prolonged hospitalization, dialysis requirement, and sepsis-related death in critically ill patients [1-7]. AKI is defined as an abrupt (within $48 \mathrm{~h}$ ) reduction in kidney function based on an elevation in serum creatinine level, a reduction in urine output, the need for renal replacement therapy (dialysis), or a combination of these factors. Unfortunately, serum creatinine is a lagging indicator of the early structural damage of AKI, rising well after the functional change in glomerular filtration rate [8-10]. This makes it

\footnotetext{
*Correspondence: cassyrc@uw.edu

'Kidney Research Institute, Division of Nephrology, Department of Medicine, University of Washington, 325 9th Ave, Box 359606, Seattle, WA 98104, USA Full list of author information is available at the end of the article
}

difficult to prospectively identify patients at risk for severe forms of AKI and related outcomes. Novel sensitive and specific biomarkers are urgently needed to provide for cost-effective and non-invasive methods to identify those at risk for severe AKI.

For many years, neutrophil gelatinase-associated lipocalin (NGAL) was considered the most promising biomarker of AKI [11-13]. However, in the setting of critical illness its use has been hampered by a confounding lack of specificity, as the inflammatory response in sepsis causes increased synthesis of NGAL in the lungs and liver, irrespective of kidney damage [10, 14-16]. Thus, NGAL may not be a useful AKI marker in patient populations where the noise from severe systemic inflammation and multi-organ damage is so pronounced.

While the pathogenesis of AKI in critically ill patients is complex, insights into the mechanisms underlying its 
course may uncover novel biomarkers. Historically, severe systemic inflammation-that is, elevated circulating levels of tumor necrosis factor (TNF), interleukin (IL)-6, granulocyte colony-stimulating factor (G-CSF) and other inflammatory mediators-was thought to play the major role in sepsis-induced organ dysfunction [17-20].

However, more recently, endothelial cell activation and subsequent vascular barrier breakdown have emerged as a critical pathogenic mechanism in organ damage [21-23]. While the exact pathogenesis of AKI in this context remains unclear, recent evidence suggests an important role for microvascular endothelial injury and dysfunction in epithelial cell injury during ischemic AKI, especially during the reperfusion phase $[9,24]$.

Angiopoietins (Ang) are angiogenic factors essential for vascular development, maturation, and inflammation. Ang-1 and its context-dependent antagonist Ang-2 are secreted endothelial growth factors which bind to the extracellular domain of the tyrosine kinase receptor Tie2 that is predominantly expressed on endothelial cells. Ang-1 can be protective, with a role in stabilizing endothelium, while Ang-2, which promotes vascular leak, can worsen outcomes in sepsis [25-28]. With activation of the endothelium, luminal adhesion molecules are upregulated, including soluble vascular cell adhesion molecule-1 (sVCAM-1) [29].

Biomarkers of endothelial injury and dysfunction have been implicated in the development of poor outcomes in diseases with systemic inflammation [30-32]. However, the clinical significance of endothelial markers in the setting of AKI has not yet been clarified.

\section{Methods}

\section{Study population}

The Harborview Medical Center (Seattle, WA, USA) SIRS cohort includes patients admitted to the intensive care unit (ICU) for more than $24 \mathrm{~h}$ and with at least two of four SIRS criteria [33, 34]. Exclusion criteria include admission for major trauma, intracranial hemorrhage, HIV, immunosuppression, or a current diagnosis of cancer. All subjects have associated plasma specimens obtained within $24 \mathrm{~h}$ of admission to the ICU, and were followed until hospital discharge or death. The institutional review board of the University of Washington approved the protocols for recruitment and sample collection, which was performed with informed consent of the participants.

\section{Biomarker measurement}

Plasma samples were thawed and concentrations of IL-6, IL-8, G-CSF, tumor necrosis factor receptor-1 (TNFR-1), Ang-1, Ang-2, and sVCAM-1 were all measured on the same day using electrochemiluminescent immunoassays (Meso Scale Discovery, Rockville, MD, USA). Samples were diluted to fit within the dynamic range of the assay, defined as the following: $0.08-2500 \mathrm{pg} / \mathrm{mL}$ for IL-6, IL-8, and TNFR-1; 0.12-5000 pg/mL for G-CSF; 3$100,000 \mathrm{pg} / \mathrm{mL}$ for Ang-1; 0.5-10,000 pg/mL for Ang-2; and $0.05-1000 \mathrm{pg} / \mathrm{mL}$ for sVCAM-1. The samples that fell below the lower or upper limits of detection were assigned those values. Missingness $(\sim 5 \%)$ in certain biomarker concentrations was due to insufficient sample volumes in a small subset of subjects.

\section{Acute kidney injury}

Serum creatinine was determined daily for the duration of the hospital stay as part of routine patient care. AKI status was determined by changes in serum creatinine in accordance with the Kidney Disease Improving Global Outcomes (KDIGO) criteria for AKI [35], from ICU admission to up to 7 days later. AKI was defined as any increase in serum creatinine by $0.3 \mathrm{mg} / \mathrm{dL}$ within $48 \mathrm{~h}$ or an increase in serum creatinine by 1.5 -fold within 7 days. Severe AKI was defined as KDIGO stages 2 or 3. Because this study was not designed with AKI as a primary endpoint, hourly urine output and renal replacement therapy data were not available to provide enough granularity to the severity of AKI definition.

\section{Covariates}

Admission data, hospital course, and complications were obtained from the electronic medical record. The APACHE (Acute Physiology, Age, Chronic Evaluation) III prognostic score and the Sequential Organ Failure Assessment (SOFA) were calculated as previously described $[36,37]$. Baseline serum creatinine was defined as creatinine at admission, and chronic kidney disease (CKD) status was defined as a glomerular filtration rate below $60 \mathrm{~mL} / \mathrm{min} / 1.73 \mathrm{~m}^{2}$ as estimated using the creatininebased CKD-EPI equation [38].

\section{Statistical analyses}

Baseline descriptive statistics on demographics, medical history, and admission characteristics were examined by AKI stage. We report continuous variables as means \pm standard deviations and categorical variables as numbers and percentages.

Plasma biomarker concentrations were tabulated by AKI stage and reported as median and interquartile range. $P$ values were obtained using Wald tests on the grouped linear AKI stage term regressed on the log-base transformed biomarker concentration.

Pearson's correlation coefficient $(\rho)$ was used to estimate the magnitude of the linear correlation between log-transformed biomarker concentrations.

For associations of biomarkers with the risk of AKI, we first defined our outcome as AKI of any stage and secondarily examined associations of biomarkers with 
severe AKI, to increase specificity of the outcome definition. Relative risk regression was used to model the probability of AKI as a function of covariates using a generalized linear model with log link and binomial error distribution [39]. In cases in which the model failed to converge with the binomial error $(\sim 10 \%$ of the models), we substituted Gaussian error and used robust standard error estimates. We used relative risk regression rather than logistic regression because the prevalence of AKI is not rare (occurring in $>22 \%$ of participants during hospitalization), hence the odds ratio is an overestimate of the relative risk.

Univariate and multivariable associations of biomarker concentrations with AKI were presented as relative risks (RRs) per standard deviation of the biomarker. The first adjustment model included baseline age, gender, admitting service (medical, surgical), body mass index, smoking status, prevalent diabetes, chronic renal insufficiency, and cirrhosis. Subsequent models added variables to the basic adjustment model that may possibly confound or mediate the associations of interest. The second model added the APACHE III score, and the final model added logtransformed circulating IL-6 concentrations.

We performed a secondary analysis to evaluate temporality issues and the potential of reverse causality, in which we repeated examination of the association of biomarkers with the AKI endpoint after exclusion of patients with AKI events occurring within the first $24 \mathrm{~h}$ of admission.

We evaluated the significance of all 32 two-way multiplicative interactions among biomarkers using the Wald test with a Bonferroni-corrected two-tailed $\alpha=0.0016$ $(0.05 / 32)$. All other $p$ values were two-tailed $(\alpha=0.05)$ and all analyses were performed using Stata release 13.1 (College Station, TX, USA).

\section{Results}

At baseline, the mean age was 55 years and $36 \%$ of patients were women. Of the 948 patients admitted, 506 (53\%) experienced an AKI event, according to KDIGO criteria. As expected, patients with AKI of higher stages were more likely to have higher APACHE III scores and higher SOFA scores, and were more likely to have been admitted to the ICU from a medical source (Table 1).

Measured concentrations of all plasma biomarkers were associated with AKI stage (all $p<0.0025$ ). Patients with higher stages of AKI had higher median concentrations of the inflammatory biomarkers IL-6, IL-8, IL-17, G-CSF, and TNFR-1, higher median concentrations of the endothelial biomarkers Ang-2, the Ang-2/Ang-1

Table 1 Baseline characteristics by AKI stage

\begin{tabular}{|c|c|c|c|c|}
\hline Variable & No AKI & AKI stage 1 & AKI stage 2 & AKI stage 3 \\
\hline N & 442 & 376 & 17 & 113 \\
\hline Age, years & $55.0(16.8)$ & $56.8(16.0)$ & $47.6(18.0)$ & $53.0(15.0)$ \\
\hline $\mathrm{BMI}, \mathrm{kg} / \mathrm{m}^{2}$ & $28.1(18)$ & $32.0(18.3)$ & $30(6.3)$ & $32.4(11.8)$ \\
\hline Creatinine, mg/dL & $0.86(0.39)$ & $1.14(0.53)$ & $0.74(0.22)$ & $3.74(3.08)$ \\
\hline SOFA score & $3(2.5)$ & $4.7(2.8)$ & $3.8(2.7)$ & $7.5(3.2)$ \\
\hline APACHE III & $42.2(24.3)$ & $55.1(27)$ & $53.6(16.5)$ & $66.5(34.8)$ \\
\hline Caucasian & $442(100)$ & $376(100)$ & $17(100)$ & $113(100)$ \\
\hline Female gender & $176(39.8)$ & $119(31.7)$ & $8(47.1)$ & $41(36.3)$ \\
\hline \multicolumn{5}{|l|}{ Source of ICU admission } \\
\hline Medical & $228(51.6)$ & $200(53.2)$ & $8(47.1)$ & $83(73.5)$ \\
\hline Surgical & $214(48.4)$ & $176(46.8)$ & $9(52.9)$ & $30(26.6)$ \\
\hline Death within 28 days & $14(3.2)$ & $63(16.8)$ & $3(17.7)$ & $31(27.4)$ \\
\hline \multicolumn{5}{|l|}{ Comorbidities } \\
\hline Chronic kidney disease & $12(2.7)$ & $34(9.0)$ & $0(0)$ & $20(17.7)$ \\
\hline Diabetes mellitus & $86(19.5)$ & $111(29.5)$ & $7(41.2)$ & $30(26.6)$ \\
\hline Cirrhosis & $36(8.1)$ & $35(9.3)$ & $3(17.7)$ & $10(8.9)$ \\
\hline Current smoking & $264(59.7)$ & $205(54.5)$ & $9(52.9)$ & $62(54.9)$ \\
\hline \multicolumn{5}{|l|}{ Source of critical illness } \\
\hline Pneumonia & $85(19.2)$ & $87(23.1)$ & $5(29.4)$ & $17(15.0)$ \\
\hline Sepsis & $269(60.9)$ & $269(71.5)$ & $14(82.4)$ & $80(70.8)$ \\
\hline Other & 74 (16.7) & 79 (21.0) & $3(17.7)$ & 21 (18.6) \\
\hline
\end{tabular}


ratio, and sVCAM-1, and lower median concentrations of Ang-1 (Table 2, Fig. 1).

There were moderate correlations between and among the endothelial biomarkers and inflammatory biomarkers. (Additional file 1). The strongest correlations between inflammatory and endothelial biomarkers were observed for Ang-2 and TNFR-1 $(\rho=0.60)$ and for Ang2 and IL-6 $(\rho=0.49)$.

After adjustment for demographics, lifestyle characteristics, and comorbidities, higher concentrations of all biomarkers were associated with the adjusted risk of AKI of any stage during hospitalization. Specifically, every standard deviation higher concentration of Ang-1 was associated with an estimated $19 \%$ lower adjusted risk of AKI (95\% confidence interval (CI): $11 \%$ lower to $33 \%$ lower, $p<0.001$; Table 3 ) and every standard deviation higher concentration of Ang-2 was associated with an estimated $22 \%$ higher risk of AKI (95 \% CI: $18 \%$ higher to $26 \%$ higher, $p<0.001$; Table 3 ).

Similarly, higher concentrations of all endothelial and inflammatory biomarkers were associated with the risk of stage 2-3 AKI during hospitalization. Specifically, every standard deviation higher concentration of Ang-1 was associated with an estimated $50 \%$ lower adjusted risk of stage 2-3 AKI (95 \% CI: 33 \% lower to 67 \% lower, $p=0.002$; Additional file 2) and every standard deviation higher concentration of Ang-2 was associated with an estimated 59 \% higher risk of stage 2-3 AKI (95\% CI: $48 \%$ higher to $72 \%$ higher, $p<0.001$; Additional file 2). Associations of endothelial biomarkers with risk of stage 2-3 AKI were robust to adjustment for the APACHE III score and for circulating IL-6.

In sensitivity analyses that excluded 173 participants with AKI events within the first $24 \mathrm{~h}$ of admission, associations were similar and more robustly similar for the endothelial biomarkers (Additional file 3). Significant two-way interactions $(p<0.001)$ among the biomarkers in association with AKI events were observed for the Ang-2/Ang-1 ratio and IL-17, VCAM, Ang-2, and GCSF, and for sVCAM with TNFR-1 and Ang-2, and for Ang-2 with TNFR-1. In a multivariable model with adjustment for all inflammatory markers and Model 1 covariates, IL-6 and TNFR-1 each remained associated with the risk of AKI. In a multivariable model with adjustment for all endothelial markers and Model 1 covariates, Ang- 1 and Ang-2 each remained associated with the risk of AKI.

\section{Discussion}

This study is the first to report associations of endothelial biomarkers with AKI in a large general medical/surgical ICU population. The results observed are consistent with previous studies, which have shown inflammatory markers to be associated with AKI events in various critically ill populations [40]. Several relatively smaller studies have recently explored associations of endothelial biomarkers and AKI. Recent case-control studies of cardiac surgery patients have found that plasma levels of Ang-2 increase post-surgically by a greater extent in patients who develop AKI than in controls [41, 42]. A cross-sectional study of critically ill patients at inception of renal replacement therapy in the ICU found that circulating Ang-2 was correlated with AKI stage and with 28-day mortality risk [43].

Accumulating evidence suggests that systemic inflammation and endothelial activation underlie the development of AKI [41, 43-46]. TNF is an inflammatory marker released by activated macrophages, monocytes,

Table 2 Plasma biomarkers according to AKI stage

\begin{tabular}{|c|c|c|c|c|c|c|}
\hline \multirow{3}{*}{$\begin{array}{l}\text { Biomarker } \\
\text { concentration }\end{array}$} & \multirow[t]{3}{*}{$N$} & \multirow{3}{*}{$\begin{array}{l}\text { No AKI } \\
\text { Median (IQR) }\end{array}$} & \multicolumn{3}{|l|}{ AKI KDIGO stage } & \multirow[b]{3}{*}{$p$-value } \\
\hline & & & \multirow{2}{*}{$\begin{array}{l}\text { Stage } 1 \\
\text { Median (IQR) }\end{array}$} & \multirow{2}{*}{$\begin{array}{l}\text { Stage } 2 \\
\text { Median (IQR) }\end{array}$} & \multirow{2}{*}{$\begin{array}{l}\text { Stage } 3 \\
\text { Median (IQR) }\end{array}$} & \\
\hline & & & & & & \\
\hline \multicolumn{7}{|l|}{ Endothelial } \\
\hline Ang-1, pg/mL & 935 & $6487.3(3160.7-10,867.1)$ & $4424.7(2084.6-8424.4)$ & $4393.3(3458.2-13,075.6)$ & $3209.9(1481.1,6574.4)$ & $<0.0001$ \\
\hline Ang-2, pg/mL & 944 & $9535.4(5740.2-17,154.9)$ & $16283.0(8491.6-32,757.3)$ & $16149.8(9764.0-22,833.7)$ & $31227.4(17316.6,67176.1)$ & $<0.0001$ \\
\hline Ang-2/Ang-1 & 935 & $1.4(0.65-4.3)$ & $3.9(1.8-13.3)$ & $2.7(1.1-7.6)$ & $9.4(3.7,34.6)$ & $<0.0001$ \\
\hline sVCAM-1, ng/mL & 944 & $497.4(402.9-699.2)$ & $569.9(446.2-803.2)$ & $708.6(485.5-1058.6)$ & $828.6(601.5,1249.9)$ & $<0.0001$ \\
\hline \multicolumn{7}{|l|}{ Inflammatory } \\
\hline $\mathrm{IL}-6, \mathrm{pg} / \mathrm{mL}$ & 891 & $99.8(46.5-233.4)$ & $151.4(63.6-420.1)$ & $174.5(82.3-461.5)$ & $171.8(102.2,400.9)$ & $<0.0001$ \\
\hline $\mathrm{IL}-8, \mathrm{pg} / \mathrm{mL}$ & 891 & $11.0(6.1-22.6)$ & $14.8(7.7-35.0)$ & $16.4(9.0-32.6)$ & $22.8(11.4,51.0)$ & $<0.0001$ \\
\hline IL-17, pg/mL & 853 & $2.5(1.1-7.2)$ & $3.8(1.4-9.7)$ & $6.8(1.7-11.6)$ & $4.6(1.7,12.1)$ & 0.0001 \\
\hline G-CSF, pg/mL & 891 & $24.1(14.2-45.8)$ & $30.3(17.2-72.6)$ & $31.7(17.6-66.9)$ & $31.3(18.2,70.6)$ & 0.0025 \\
\hline TNFR-1, pg/mL & 891 & $6281.3(4565.8-9790.6)$ & $9952.6(6411.5-14,879.7)$ & $8910.5(5198.26-19,151.48)$ & $31474.3(18514.3,47995.3)$ & $<0.0001$ \\
\hline
\end{tabular}

$A K I$ acute lung injury, Ang angiopoietin, G-CSF granulocyte colony-stimulating factor, IL interleukin, IQR interquartile range, KDIGO Kidney Disease Improving Global Outcomes, TNFR-1 tumor necrosis factor receptor 1, SVCAM-1 soluble vascular cell adhesion molecule-1 


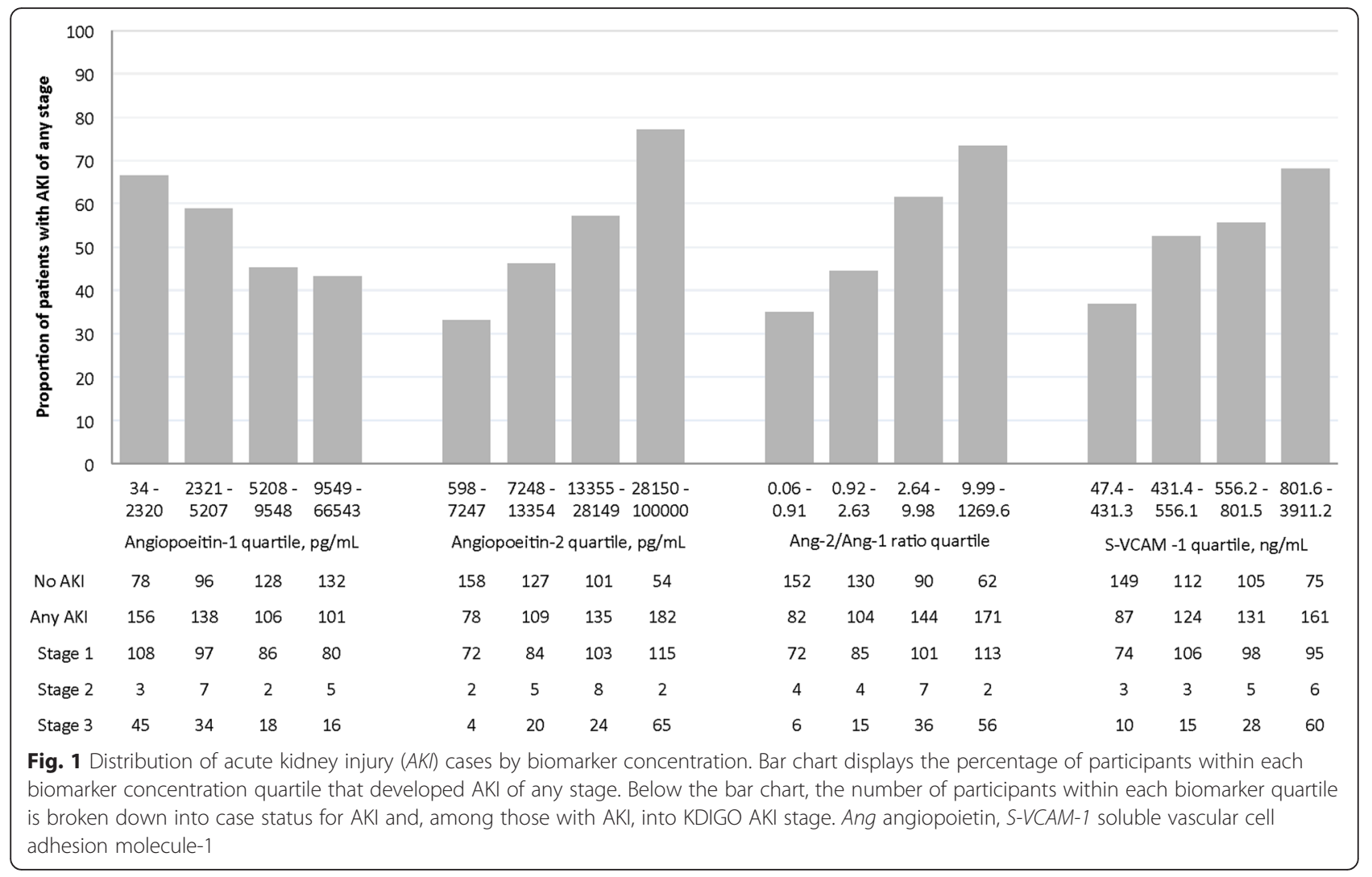

Table 3 Associations of biomarkers with acute kidney injury (any stage)

\begin{tabular}{|c|c|c|c|c|}
\hline Biomarkers & $\begin{array}{l}\text { Unadjusted RR } \\
(95 \% \mathrm{Cl})\end{array}$ & $\begin{array}{l}\text { Adjusted RR } \\
(95 \% \mathrm{Cl})\end{array}$ & $\begin{array}{l}\text { APACHE III-adjusted RR } \\
(95 \% \mathrm{Cl})\end{array}$ & $\begin{array}{l}\text { IL6-adjusted RR } \\
(95 \% \mathrm{Cl})\end{array}$ \\
\hline \multicolumn{5}{|l|}{ Endothelial } \\
\hline Ang-1 & $0.81(0.74-0.88)^{* * *}$ & $0.81(0.73-0.89)^{* * *}$ & $0.87(0.80-0.95)^{* *}$ & $0.85(0.77-0.93)^{* * *}$ \\
\hline Ang-2 & $1.22(1.19-1.25)^{* * *}$ & $1.22(1.18-1.26)^{* * *}$ & $1.16(1.11-1.20)^{* * *}$ & $1.17(1.13-1.22)^{* * *}$ \\
\hline Ang-2/Ang-1 & $1.06(1.03-1.08)^{* * *}$ & $1.06(1.03-1.08)^{* * *}$ & $1.04(1.02-1.06)^{* * *}$ & $1.05(1.03-1.07)^{* * *}$ \\
\hline sVCAM-1 & $1.09(1.07-1.12)^{* * *}$ & $1.17(1.12-1.21)^{* * *}$ & $1.13(1.07-1.18)^{* * *}$ & $1.14(1.10-1.19)^{* * *}$ \\
\hline \multicolumn{5}{|l|}{ Inflammatory } \\
\hline IL-6 & $1.10(1.07-1.14)^{* * *}$ & $1.10(1.06-1.14)^{* * *}$ & $1.04(1.00-1.08)$ & - \\
\hline |L-8 & $1.04(1.01-1.07)^{*}$ & $1.04(1.02-1.07)^{* *}$ & $1.01(0.98-1.03)$ & $1.01(0.98-1.04)$ \\
\hline $\mid \mathrm{LL}-17$ & $1.07(1.05-1.10)^{* * *}$ & $1.06(1.03-1.09)^{* * *}$ & $1.05(1.02-1.08)^{* *}$ & $1.04(1.00-1.07)^{*}$ \\
\hline G-CSF & $1.06(1.03-1.10)^{* *}$ & $1.06(1.03-1.10)^{* *}$ & $1.01(0.97-1.06)$ & $0.99(0.95-1.04)$ \\
\hline TNFR-1 & $1.21(1.18-1.23)^{* * *}$ & $1.20(1.17-1.22)^{* * *}$ & $1.16(1.14-1.19)^{* * *}$ & $1.17(1.15-1.20)^{* * *}$ \\
\hline
\end{tabular}

Relative risks (RR) presented per standard deviation of each biomarker

${ }^{a}$ Relative risk regression adjusted for age, gender, sepsis, admitting service (ex: medical = 1, surgical = 0 ), body mass index, smoking status, diabetes mellitus, chronic renal insufficiency, and cirrhosis

${ }^{\mathrm{b}}$ Adjusted for APACHE III and covariates in ${ }^{\text {a }}$

${ }^{c}$ Adjusted for $\log _{2}$ (IL-6) concentration and covariates in ${ }^{a}$

${ }^{*} p<0.05 ;{ }^{* *} p<0.01 ;{ }^{* * *} p<0.001$

Ang angiopoietin, APACHE Acute Physiology, Age, Chronic Evaluation, Cl confidence interval, G-CSF granulocyte colony-stimulating factor, IL interleukin, TNFR-1 tumor necrosis factor receptor 1, sVCAM-1 soluble vascular cell adhesion molecule-1 
and neutrophils, and has been shown to have a major role in both sepsis and septic AKI [20, 47-49]. Renal endothelial cells are activated by TNF, further perpetuating the pro-inflammatory state and potentially sensitizing kidney tissue to subsequent damage [47, 48]. Recent efforts in animal models have demonstrated that Ang-1 may enhance the protective capacity of early endothelial outgrowth cells in murine AKI [50,51]. Acute endothelial cell changes may lead to altered vascular reactivity, permeability, adherence of leukocytes, coagulation, and microvascular vasomotor autoregulation, perpetuating AKI.

Among a large cohort of critically ill patients admitted to the ICU, we found that circulating concentrations of inflammatory and endothelial biomarkers were significantly associated with a higher risk of AKI.

These biomarkers may highlight novel pathways of kidney injury in the setting of critical illness as well as the potential use of baseline biomarker profiles to identify individuals at risk of developing AKI. Our observations support the hypothesis that, before overt renal cellular injury has occurred, there may be alterations in microcirculation and tissue oxygenation that predispose individuals to renal damage [52]. This concept is especially relevant to the SIRS state, where inflammation and endothelial cell activation are prominent [16]. The microvasculature and endothelial cells in particular regulate blood flow to local tissue beds and modulate coagulation, inflammation, and vascular permeability. AKI has profound effects on the renal endothelium, resulting in microvascular dysfunction leading to ongoing ischemic conditions and further injury following the initial insult $[53,54]$.

While we highlight, for the first time, the independent association of endothelial biomarkers with AKI in critically ill patients, our study has some limitations. The most important limitation of this observational study is the potential for confounding, because characteristics such as illness severity are likely linked both with endothelial dysregulation and risk of AKI. Substantial efforts were made to adjust for potential confounding, but a causal association between the dysfunction of endothelial cells and AKI development cannot be established from our results. Second, this study was not designed with AKI as a primary endpoint and, as such, did not collect sufficiently detailed urine output data; AKI was only assessed retrospectively by changes in creatinine [34]. Data were not available on renal replacement therapy, which would have provided additional granularity to the severity of AKI definition. Moreover, sepsis decreases production of creatinine, limiting the use of changes in creatinine levels as a marker of AKI [55]. A small proportion of patients had insufficient sample volumes to measure all biomarkers simultaneously. These measurement issues may have resulted in non-differential misclassification, leading to an attenuation of associations toward the null. Third, we cannot exclude the possibility of reverse causality, wherein the damaged kidney itself may release endothelial markers before creatinine rises, and thus contributes to higher circulating levels of Ang-2 and lower circulating levels of Ang-1 [56]. Lastly, the subjects included in this study are all recruited from a single hospital and were all Caucasian, and this may limit the ability to more broadly interpret our results. We did, however, include subjects transferred from outside hospitals in the analyses and adjustment for this factor did not modify the associations with poor outcome.

\section{Conclusions}

In conclusion, endothelial and inflammatory markers were significantly associated with AKI among patients in critical care. Further studies are needed to investigate the prognostic value of these biomarkers and to potentially identify interventions that modify these biomarkers.

\section{Additional files}

Additional file 1: Pairwise correlation matrix of endothelial and inflammatory biomarkers. Pearson's correlation coefficient $(\rho)$ was used to estimate the magnitude of the linear correlation between log-transformed biomarker concentrations. (DOCX $15 \mathrm{~kb}$ )

Additional file 2: Associations of biomarkers with AKI (Stage 2-3 versus no AKI). For associations of biomarkers with the risk of AKI, we examined associations of biomarkers with severe AKI, to increase specificity of the outcome definition. (DOCX $15 \mathrm{~kb}$ )

Additional file 3: Associations of biomarkers with AKI (any stage) after exclusion of 173 patients with AKI within the first $24 \mathrm{~h}$ of admission. We performed a secondary analysis to evaluate temporality issues and the potential of reverse causality, in which we repeated examination of the association of biomarkers with the AKI endpoint after exclusion of patients with $\mathrm{AKl}$ events occurring within the first $24 \mathrm{~h}$ of admission. (DOCX $15 \mathrm{~kb}$ )

\section{Abbreviations}

AKI, acute kidney injury; Ang, angiopoietin; APACHE, Acute Physiology, Age, Chronic Evaluation; Cl, confidence interval; CKD, chronic kidney disease; G-CSF, granulocyte colony-stimulating factor; ICU, intensive care unit; IL, interleukin; KDIGO, Kidney Disease Improving Global Outcomes;NGAL, neutrophil gelatinase-associated lipocalin; RR, relative risk; SIRS, systemic inflammatory response syndrome; SOFA, Sequential Organ Failure Assessment; sTNFR-1, tumor necrosis factor receptor 1; sVCAM-1, soluble vascular cell adhesion molecule-1; TNF, tumor necrosis factor

\section{Acknowledgments}

The authors thank all of the SIRS study participants and coordinators. This article is the result of work supported by an unrestricted gift from the Northwest Kidney Centers to the Kidney Research Institute (Seattle, WA, USA). This research was also supported by the National Institutes of Health (grant K23HL120896 and Parker B Francis Fellowship to CM).

\section{Authors' contributions}

CRC had full access to all of the data in the study and takes responsibility for the integrity of the data and the accuracy of the data analysis. CRC, RK, CM, $\mathrm{JH}, \mathrm{WCL}$, and MMW conceived of and designed the study and helped to draft the manuscript. CRC, RK, and BLP were responsible for the analysis and interpretation of data. SHB provided administrative, technical and material support. JH, WCL, and MMW were responsible for study supervision. CRC RK, BLP, SHB, CM, JH, WCL, and MMW performed critical revision of the manuscript for important intellectual content. All authors read and approved the final manuscript. 


\section{Competing interests}

The authors declare that they have no competing interests.

\section{Author details}

${ }^{1}$ Kidney Research Institute, Division of Nephrology, Department of Medicine, University of Washington, 325 9th Ave, Box 359606, Seattle, WA 98104, USA. ${ }^{2}$ Department of Biostatistics, University of Washington, Seattle, WA, USA ${ }^{3}$ Division of Pulmonary and Critical Care Medicine, Department of Medicine, University of Washington, Seattle, WA, USA. ${ }^{4}$ Center for Lung Biology, Division of Allergy and Infectious Diseases, Department of Medicine, University of Washington, Seattle, WA, USA

Received: 11 January 2016 Accepted: 14 June 2016 Published online: 03 July 2016

\section{References}

1. Chertow GM, Burdick E, Honour M, Bonventre JV, Bates DW. Acute kidney injury, mortality, length of stay, and costs in hospitalized patients. J Am Soc Nephrol. 2005;16(11):3365-70.

2. Waikar SS, Liu KD, Chertow GM. Diagnosis, epidemiology and outcomes of acute kidney injury. Clin J Am Soc Nephrol. 2008;3(3):844-61.

3. Rangel-Frausto MS, Pittet D, Costigan M, Hwang T, Davis CS, Wenzel RP. The natural history of the systemic inflammatory response syndrome (SIRS). A prospective study. JAMA. 1995;273(2):117-23.

4. Zarjou A, Agarwal A. Sepsis and acute kidney injury. J Am Soc Nephrol. 2011;22(6):999-1006.

5. Poukkanen M, Wilkman E, Vaara ST, Pettilä V, Kaukonen KM, Korhonen AM, et al. Hemodynamic variables and progression of acute kidney injury in critically ill patients with severe sepsis: data from the prospective observational FINNAKI study. Crit Care. 2013;17(6):R295.

6. Bouchard J, Acharya A, Cerda J, Maccariello ER, Madarasu RC, Tolwani AJ, et al. A prospective international multicenter study of AKI in the intensive care unit. Clin J Am Soc Nephrol. 2015:10(8):1324-31.

7. Libório AB, Leite T, Neves FM, Teles F, Bezerra CT. AKI complications in critically ill patients: association with mortality rates and RRT. Clin J Am Soc Nephrol. 2015;10(1):21-8

8. Murray PT, Devarajan P, Levey AS, Eckardt KU, Bonventre JV, Lombardi R, et al. A framework and key research questions in AKI diagnosis and staging in different environments. Clin J Am Soc Nephrol. 2008;3(3):864-8.

9. Devarajan P. Update on mechanisms of ischemic acute kidney injury. J Am Soc Nephrol. 2006;17(6):1503-20.

10. Nickolas TL, Barasch J, Devarajan P. Biomarkers in acute and chronic kidney disease. Curr Opin Nephrol Hypertens. 2008;17(2):127-32.

11. Haase M, Bellomo R, Devarajan P, Schlattmann P, Haase-Fielitz A. NGAL Meta-analysis Investigator Group. Accuracy of neutrophil gelatinaseassociated lipocalin (NGAL) in diagnosis and prognosis in acute kidney injury: a systematic review and meta-analysis. Am J Kidney Dis. 2009;54(6):1012-24.

12. Supavekin S, Zhang W, Kucherlapati R, Kaskel FJ, Moore LC, Devarajan P. Differential gene expression following early renal ischemia/reperfusion. Kidney Int. 2003;63(5):1714-24.

13. Mishra J, Dent C, Tarabishi R, Mitsnefes MM, Ma Q, Kelly C, et al. Neutrophi gelatinase-associated lipocalin (NGAL) as a biomarker for acute renal injury after cardiac surgery. Lancet. 2005;365(9466):1231-8.

14. Nickolas TL, Forster CS, Sise ME, Barasch N, Solá-Del Valle D, Viltard M, et al. NGAL (LCn2) monomer is associated with tubulointerstitial damage in chronic kidney disease. Kidney Int. 2012;82(6):718-22.

15. Devarajan P. NGAL for the detection of acute kidney injury in the emergency room. Biomark Med. 2014;8(2):217-9.

16. Marino R, Struck J, Maisel AS, Magrini L, Bergmann A, Di Somma S. Plasma adrenomedullin is associated with short-term mortality and vasopressor requirement in patients admitted with sepsis. Crit Care. 2014;18(1):R34.

17. Dinarello CA. Proinflammatory and anti-inflammatory cytokines as mediators in the pathogenesis of septic shock. Chest. 1997;112(6 Suppl):321S-9S

18. Nechemia-Arbely Y, Barkan D, Pizov G, Shriki A, Rose-John S, Galun E, et al. IL-6/IL-6R axis plays a critical role in acute kidney injury. J Am Soc Nephrol. 2008;19(6):1106-15.

19. Bagshaw SM, Langenberg C, Haase M, Wan L, May CN, Bellomo R. Urinary biomarkers in septic acute kidney injury. Intensive Care Med. 2007;33(7):1285-96.
20. Xu C, Chang A, Hack BK, Eadon MT, Alper SL, Cunningham PN. TNFmediated damage to glomerular endothelium is an important determinant of acute kidney injury in sepsis. Kidney Int. 2014;85(1):72-81.

21. Powell TC, Powell SL, Allen BK, Griffin RL, Warnock DG, Wang HE. Association of inflammatory and endothelial cell activation biomarkers with acute kidney injury after sepsis. Springerplus. 2014;3:207.

22. Aird WC. Vascular bed-specific hemostasis: role of endothelium in sepsis pathogenesis. Crit Care Med. 2001;29(7 Suppl):S28-34; discussion S34-5.

23. Volk T, Kox WJ. Endothelium function in sepsis. Inflamm Res. 2000;49(5):185-98

24. Bonventre JV, Yang L. Cellular pathophysiology of ischemic acute kidney injury. J Clin Invest. 2011;121(11):4210-21.

25. Fiedler $\mathrm{U}$, Augustin HG. Angiopoietins: a link between angiogenesis and inflammation. Trends Immunol. 2006:27(12):552-8.

26. David S, Mukherjee A, Ghosh CC, Yano M, Khankin EV, Wenger JB, et al. Angiopoietin-2 may contribute to multiple organ dysfunction and death in sepsis. Crit Care Med. 2012;40(11):3034-41.

27. Ricciuto DR, dos Santos CC, Hawkes M, Toltl $\amalg$, Conroy AL, Rajwans N, et al. Angiopoietin-1 and angiopoietin-2 as clinically informative prognostic biomarkers of morbidity and mortality in severe sepsis. Crit Care Med. 2011;39(4):702-10

28. Xing K, Murthy S, Liles WC, Singh JM. Clinical utility of biomarkers of endothelial activation in sepsis—a systematic review. Crit Care. 2012;16(1):R7.

29. Su CM, Cheng HH, Tsai TC, Hsiao SY, Tsai NW, Chang WN, et al. Elevated serum vascular cell adhesion molecule-1 is associated with septic encephalopathy in adult community-onset severe sepsis patients. Biomed Res Int. 2014;2014:598762.

30. Thurston G, Rudge JS, loffe E, Zhou H, Ross L, Croll SD, et al. Angiopoietin-1 protects the adult vasculature against plasma leakage. Nat Med. 2000;6(4):460-3.

31. Agrawal A, Matthay MA, Kangelaris KN, Stein J, Chu JC, Imp BM, et al. Plasma angiopoietin-2 predicts the onset of acute lung injury in critically ill patients. Am J Respir Crit Care Med. 2013;187(7):736-42.

32. Parikh SM, Mammoto T, Schultz A, Yuan HT, Christiani D, Karumanchi SA, et al. Excess circulating angiopoietin-2 may contribute to pulmonary vascular leak in sepsis in humans. PLoS Med. 2006:3(3):e46.

33. Bone RC, Balk RA, Cerra FB, Dellinger RP, Fein AM, Knaus WA, et al. Definitions for sepsis and organ failure and guidelines for the use of innovative therapies in sepsis. The ACCP/SCCM Consensus Conference Committee. American College of Chest Physicians/Society of Critical Care Medicine. 1992. Chest. 2009;136(5 Suppl):e28.

34. Mikacenic C, Hahn WO, Price BL, Harju-Baker S, Katz R, Kain KC, et al. Biomarkers of endothelial activation are associated with poor outcome in critical illness. PLoS One. 2015;10(10):e0141251.

35. Group KDIGOKC-MW. KDIGO clinical practice guideline for the diagnosis, evaluation, prevention, and treatment of Chronic Kidney Disease-Mineral and Bone Disorder (CKD-MBD). Kidney Int Suppl. 2009;113:S1-130.

36. Knaus WA, Wagner DP, Draper EA, Zimmerman JE, Bergner M, Bastos PG, et al. The APACHE III prognostic system. Risk prediction of hospital mortality for critically ill hospitalized adults. Chest. 1991;100(6):1619-36.

37. Vincent JL, Moreno R, Takala J, Willatts S, De Mendonça A, Bruining H, et al. The SOFA (Sepsis-related Organ Failure Assessment) score to describe organ dysfunction/failure. On behalf of the Working Group on Sepsis-Related Problems of the European Society of Intensive Care Medicine. Intensive Care Med. 1996;22(7):707-10

38. Inker LA, Schmid CH, Tighiouart H, Eckfeldt JH, Feldman HI, Greene T, et al. Estimating glomerular filtration rate from serum creatinine and cystatin C. N Engl J Med. 2012;367(1):20-9.

39. Lumley $\mathrm{T}$, Kronmal $\mathrm{R}$, Ma S. Relative risk regression in medical research: models, contrasts, estimators, and algorithms. 2006.

40. Chawla LS, Seneff MG, Nelson DR, Williams M, Levy H, Kimmel PL, et al. Elevated plasma concentrations of IL-6 and elevated APACHE II score predict acute kidney injury in patients with severe sepsis. Clin J Am Soc Nephrol. 2007;2(1):22-30.

41. Jongman RM, van Klarenbosch J, Molema G, Zijlstra JG, de Vries AJ, van Meurs M. Angiopoietin/Tie2 dysbalance is associated with acute kidney injury after cardiac surgery assisted by cardiopulmonary bypass. PLoS One. 2015;10(8):e0136205.

42. Liu KL, Lee KT, Chang CH, Chen YC, Lin SM, Chu PH. Elevated plasma thrombomodulin and angiopoietin-2 predict the development of acute kidney injury in patients with acute myocardial infarction. Crit Care. 2014;18(3):R100.

43. Kümpers $\mathrm{P}$, Hafer $\mathrm{C}$, David S, Hecker H, Lukasz A, Fliser D, et al. Angiopoietin-2 in patients requiring renal replacement therapy in the ICU: relation to acute kidney injury, multiple organ dysfunction syndrome and outcome. Intensive Care Med. 2010;36(3):462-70. 
44. Liu KD, Glidden DV, Eisner MD, Parsons PE, Ware LB, Wheeler A, et al. Predictive and pathogenetic value of plasma biomarkers for acute kidney injury in patients with acute lung injury. Crit Care Med. 2007;35(12):2755-61.

45. Iglesias J, Marik PE, Levine JS, Investigators NIS. Elevated serum levels of the type I and type I| receptors for tumor necrosis factor-alpha as predictive factors for ARF in patients with septic shock. Am J Kidney Dis. 2003;41(1):62-75.

46. Bautista E, Arcos M, Jimenez-Alvarez L, García-Sancho MC, Vázquez ME, Peña $E$, et al. Angiogenic and inflammatory markers in acute respiratory distress syndrome and renal injury associated to A/H1N1 virus infection. Exp Mol Pathol. 2013;94(3):486-92.

47. Aird WC. Endothelium as a therapeutic target in sepsis. Curr Drug Targets. 2007;8(4):501-7.

48. Wolfs TG, Buurman WA, van Schadewijk A, de Vries B, Daemen MA, Hiemstra PS, et al. In vivo expression of Toll-like receptor 2 and 4 by renal epithelial cells: IFN-gamma and TNF-alpha mediated up-regulation during inflammation. J Immunol. 2002;168(3):1286-93.

49. Wan L, Bellomo R, Di Giantomasso D, Ronco C. The pathogenesis of septic acute renal failure. Curr Opin Crit Care. 2003;9(6):496-502.

50. Patschan D, Rinneburger J, Idrizi N, Backhaus R, Schwarze K, Henze E, et al. Angiopoietin-1 treated early endothelial outgrowth cells (eEOCs) are activated in vitro and reduce renal damage in murine acute ischemic kidney injury (iAKI). BMC Nephrol. 2013;14:227.

51. Patschan D, Backhaus R, Elle HJ, Schwarze K, Henze E, Becker JU, et al. Angiopoietin-2 modulates eEOC-mediated renoprotection in AKI in a dose-dependent manner. J Nephrol. 2013;26(4):667-74.

52. Okusa MD, Jaber BL, Doran P, Duranteau J, Yang L, Murray PT, et al. Physiological biomarkers of acute kidney injury: a conceptual approach to improving outcomes. Contrib Nephrol. 2013;182:65-81.

53. Sutton TA, Fisher CJ, Molitoris BA. Microvascular endothelial injury and dysfunction during ischemic acute renal failure. Kidney Int. 2002;62(5):1539-49.

54. Sutton TA, Mang HE, Campos SB, Sandoval RM, Yoder MC, Molitoris BA. Injury of the renal microvascular endothelium alters barrier function after ischemia. Am J Physiol Renal Physiol. 2003;285(2):F191-198.

55. Doi K, Yuen PS, Eisner C, Hu X, Leelahavanichkul A, Schnermann J, et al. Reduced production of creatinine limits its use as marker of kidney injury in sepsis. J Am Soc Nephrol. 2009;20(6):1217-21.

56. de Vries DK, Khairoun M, Lindeman JH, Bajema IM, de Heer E, Roest M, et al Renal ischemia-reperfusion induces release of angiopoietin-2 from human grafts of living and deceased donors. Transplantation. 2013;96(3):282-9.

\section{Submit your next manuscript to BioMed Central and we will help you at every step:}

- We accept pre-submission inquiries

- Our selector tool helps you to find the most relevant journal

- We provide round the clock customer support

- Convenient online submission

- Thorough peer review

- Inclusion in PubMed and all major indexing services

- Maximum visibility for your research

Submit your manuscript at www.biomedcentral.com/submit 